\title{
Pengaruh Iklan di Instagram Dan Word Of Mouth Terhadap Minat Beli Online Melalui Aplikasi Shopee: Studi Kasus Pada Mahasiswa Fakultas Ekonomi Universitas Nasional Pasim
}

\author{
Ayi Muhiban dan Yanti Permatasari \\ Universitas Nasional Pasim, Indonesia \\ Email korepondensi: ayimuhiban@ pasim.ac.id/yantipermatasa1@gmail.com
}

\begin{abstract}
ABSTRAK
Penelitian ini dilakukan pada Mahasiswa Fakultas Ekonomi Universitas Nasional Pasim yang berbelanja $\emptyset$ nline di Shopee. Tujuan dari penelitian ini adalah untuk mengetahui seberapa besar kontribusi pengaruh iklan dan word of mouth terhadap minat beli baik secara parsial maupun simultan pada Shopee. Metode penelitian yang akan digunakan dalam penelitian ini adalah metode deskriptif dan metode asosiatif. Pada penelitian ini yang menjadi unit analisisnya adalah individu yaitu Mahasiswa Fakultas Ekonomi Kelas Regular Sore Universitas Nasional Pasim yang berbelanja online di Shopee. Sampel dalam penelitian ini sebanyak 126 responden. Pengambilan sampel acak bertingkat proporsional adalah teknik penarikan sampel yang digunakan dalam penelitian ini. Metode analisis menggunakan analisis regresi linear berganda, selain itu juga dilakukan pengujian validitas dan reliabilitas instrumen penelitian. Berdasarkan hasil penelitian menunjukkan bahwa terdapat pengaruh baik secara parsial maupun simultan pada variabel eksogen (iklan dan word of mouth) terhadap variabel endogen (minat beli). Implikasi dari penelitian ini bahwa Shopee dapat meninjau kembali pesan/caption dengan memperjelas keterangan dari gambar yang ditampilkan, memperhatikan hal-hal terkait informasi negatif yang biasanya mudah sampai dari konsumen ke konsumen dan meningkatkan pelayanan agar konsumen merasa puas.
\end{abstract}

Kata Kunci: Iklan, Word Of Mouth, Minat Beli

\begin{abstract}
This research was conducted on students of the Faculty of Economics, Pasim National University who shop online at Shopee. The purpose of this research is to find out how big the contribution of the influence of advertising and word of mouth to buying interest either partially or simultaneously at Shopee. The research method that will be used in this research is descriptive method and associative method. In this study, the unit of analysis is the individual, namely the students of the Faculty of Economics in the Regular Afternoon Class at Pasim National University who shop online at Shopee. The sample in this study were 126 respondents. Proportional stratified random sampling is the sampling technique used in this study. The method of analysis used multiple linear regression analysis, in addition to testing the validity and reliability of the research instrument. Based on the results of the study, it shows that there is an influence either partially or simultaneously on exogenous variables (advertising and word of mouth) on endogenous variables (buying interest). The implication of this research is that Shopee can review the message/caption by clarifying the description of the displayed image, paying attention to things related to negative information which is usually easy to get from consumer to consumer and improving services so that consumers feel satisfied.
\end{abstract}

Keywords: Advertising, Word Of Mouth, Purchase Interest 


\section{PENDAHULUAN}

Perkembangan teknologi informasi di era globalisasi ini memberikan dampak terhadap kehidupan masyarakat baik dalam lingkup sosial, ekonomi maupun budaya. Hal itu ditandai dengan semakin canggihnya peralatan sarana dan prasarana yang mendukung setiap kegiatan dalam pemenuhan kebutuhan manusia dan memudahkan kita berkomunikasi, mencari informasi, mengakses berita dunia hingga berbelanja online melalui internet. Internet telah mengubah gaya hidup masyarakat, salah satunya dalam hal kebiasaan berbelanja online melalui situs atau aplikasi e-commerce. Perusahaan aplikasi belanja online yang hadir di Indonesia banyak bermunculan seperti Shopee, Lazada, Bukalapak, Tokopedia, BliBli dan lain-lain. Berdasarkan data Similarweb jumlah kunjungan platform e-commerce pada kuartal II (AprilJuni), Tokopedia tercatat paling banyak dikunjungi mencapai 139,2 juta kali, Shopee tercatat mengantongi kunjungan bulanan 115 juta, Bukalapak 26,54 juta, Lazada 25,19 juta dan Blibli 17,44 juta.

Persaingan komersial, perusahaan harus mampu memberikan Salah satu media sosial yang populer digunakan dalam pemasaran media sosial adalah Instagram. Instagram merupakan aplikasi berbagi foto yang akhir-akhir ini sangat populer. Instagram memiliki kekuatan dahsyat di bidang visual. Keunggulan Instagram sebagai alat pemasaran adalah Instagram dapat menyampaikan informasi brand melalui foto/gambar atau video berdurasi 60 detik. Instagram tidak lagi hanya muncul sebagai media sosial di dunia maya, tetapi sebagai pilihan baru untuk melancarkan aktivitas pemasaran. Forbes bahkan menggambarkan Instagram sebagai alat penjualan yang sangat kuat. Sebagai media visual, Instagram dapat menarik perhatian terutama untuk bisnis atau brand dalam bentuk fisik (http://www.marketing.co.id/dulang-sukses-pemasaran-instagram-ini-strateginya/, diakses tanggal 7 September 2021).

Periklanan sangat penting bagi perusahaan untuk memperkenalkan produknya kepada konsumen terutama pada perusahaan yang memiliki produk baru. Iklan seharusnya tidak hanya menargetkan produk baru, tetapi juga produk yang sudah ada sejak lama. Hal ini dilakukan agar merek tetap eksis dan tidak tergantikan oleh produk baru yang masuk ke pasar. Iklan itu sendiri harus dapat membimbing konsumen untuk membeli produk yang dirancang oleh departemen periklanan agar percaya dapat memenuhi kebutuhan dan keinginan pembeli. Tujuan beriklan di media adalah untuk memperkenalkan produk, termasuk membujuk calon konsumen untuk membangkitkan minat beli. Konsumen yang termotivasi siap untuk melakukan tindakan pembelian Melalui tindakan dan objek pembelajaran, konsumen memperoleh keyakinan yang mempengaruhi perilaku pembelian(Daulay, 2014).

Word of mouth memiliki peran penting di dalam mempengaruhi pembentukan sikap dan perilaku konsumen. Disebutkan juga bahwa word of mouth memberikan pengaruh yang kuat terhadap pembelian dibandingkan media-media komunikasi tradisional lainnya seperti iklan maupun pembelian rekomendasi editorial. Komunikator dalam word of mouth biasanya berasal dari keluarga, teman terdekat maupun orang lain yang pernah menggunakan atau mempunyai pengalaman berbelanja online di shopee. Pengalaman yang akan disampaikan pada word of mouth tidak hanya pengalaman baik pada saat berbelanja online di shopee saja namun juga mengenai kelemahan maupun pengalaman tidak baik ketika menggunakan aplikasi shopee dalam berbelanja online. Pengalaman baik atau buruk ini dapat mempengaruhi minat beli seseorang dalam berbelanja online (Dwi Putranti dkk, 2016). 


\section{METODE PENELITIAN}

\section{Jenis Penelitian}

Penelitian ini menggunakan metode penelitian kuantitatif dengan pendekatan deskriptif dan asosiatif. Deskriptif adalah statistic yang digunakan untuk menganalisis dengan cara mendeskripsikan atau menggambarkan data yang telah terkumpul sebagaimana adanya tanpa bermaksud membuat kesimpulan yang berlaku untuk umum atau generalisasi, sedangkan Asosiatif adalah suatu bentuk fenomena yang menunjukan adanya hubungan antara dua atau lebih variabel (S. Soedibjo, 2013:174).

\section{Unit Analisis}

Unit analisis adalah unit yang akan digunakan untuk menjelaskan atau menggambarkan karakteristik dari kumpulan objek yang lebih besar lagi(S. Soedibjo, 2013:50). Dalam penelitian ini yang menjadi unit analisis adalah individu yaitu MahasiswaFakultas Ekonomi Kelas Regular Sore Universitas Nasional Pasim yang berbelanja online di Shopee.

\section{Populasi}

Populasi adalah wilayah generalisasi yang terdiri atas, obyek/subyek yang mempunyai kualitas dan karakteristik tertentu yang ditetapkan oleh peneliti untuk dipelajari dan kemudian ditarik kesimpulannya (Sugiyono, 2017:119). Populasi penelitian ini adalah MahasiswaFakultas Ekonomi Kelas Regular Sore Universitas Nasional Pasim sebanyak 185 orang.

\section{Sampel}

sampel adalah bagian dari jumlah dan karakteristik yang dimiliki oleh populasi (Sugiyono, 2017:81). Sampel dalam penelitian ini menggunakan rumus Yamane (S. Soedibjo, 2013:141) dengan persisi dan akurasi sebesar $5 \%$ adalah sebagai berikut:

$$
\mathrm{n}=\frac{N}{N \cdot d^{2}+1}=\frac{185}{185(0.05)^{2}+1}=126
$$

\section{Sumber Data}

Pada penelitian ini metode pengumpulan data menggunakan data primer dan data sekunder.

Data Primer

Data primer adalah sumber data yang langsung memberikan data kepada pengumpul data (Sugiyono, 2017:137). Dalam penelitian ini sumber data primer adalah kuesioner. Kuesioner (angket) adalah teknik pengumpulan data yang dilakukan dengan cara memberi seperangkat pertanyaan atau pernyataan tertulis kepada responden untuk dijawabnya (Sugiyono, 2017:142).

\section{Data Sekunder}

Data sekunder adalah adalah sumber yang tidak langsung memberikan data kepada pengumpul data (Sugiyono, 2017:137). Dalam penelitian ini yangmenjadi sumber data sekunder adalah artikel, jurnal, serta situs di internet yang berkenaan dengan penelitian yang dilakukan. 


\section{HASIL DAN PEMBAHASAN}

\section{Distribusi Frekuensi dan Pembobotan Variabel Iklan}

Berdasarkan tabel distribusi frekuensi diatas,dapat disimpulkan bahwa variabel iklan terdiri 6 pernyataan dengan nilai rata-rata bobot aktual sebesar 501, nilai tersebut termasuk kategori baik karena berada pada interval 428 - 528. Hasil diatas terdapat nilai bobot aktual terendah pada pernyataan "Pesan yang terdapat dalam iklan Shopee mudah dipahami" dengan nilai bobot aktual sebesar 494. Terdapat pernyataan dengan nilai bobot aktual tertinggi yaitu pada pernyataan "Iklan Shopee di instagram memunculkan keinginan untuk menjadi pengguna Shopee" dengan nilai bobot aktual 511.

\section{Variabel Word Of Mouth (X2)}

Berdasarkan tabel distribusi frekuensi diatas, dapat disimpulkan bahwa variabel word of mouth memiliki nilai rata-rata bobot aktual sebesar 499, nilai tersebut termasuk kategori baik karena berada pada interval 428 - 528. Hasil diatas terdapat nilai bobot aktual terendah pada pernyataan "Saya memperoleh informasi tentang produk yang dibeli sesuai dengan yang dipesan" dengan nilai bobot aktual sebesar 493. Terdapat dua pernyataan dengan nilai tertinggi yaitu pada pernyataan "Saya sering mendengar pembicaraan mengenai Shopee dibandingkan marketplace lainnya" dan "Saya mendapatkan infomasi mengenai banyaknya promo yang ditawarkan oleh Shopee" dengan nilai bobot aktual sebesar 502.

\section{Variabel Minat Beli $(Y)$}

Distribusi frekuensi dan pembobotan dari masing-masing indikator pada variabel minat beli maka diketahui datanya sebagai berikut:

Berdasarkan tabel distribusi frekuensi diatas, dapat disimpulkan bahwa variabel iklan terdiri 6 pernyataan dengan nilai rata-rata bobot aktual sebesar 496, nilai tersebut termasuk kategori baik karena berada pada interval 428 - 528. Hasil diatas terdapat nilai bobot aktual terendah pada pernyataan "Saya merasa puas, tidak akan beralih ke situs belanja lain setelah menggunakan Shopee" dengan nilai bobot aktual sebesar 482. Terdapat pernyataan dengan nilai tertinggi yaitu pada pernyataan "Saya ingin mengetahui lebih banyak mengenai jenis produk yang ada di Shopee" dengan nilai bobot aktual 519.

\section{Uji Validitas dan Reliabilitas}

\section{Uji Validitas}

Dari tabel setiap item pertanyaan bahwa nilai $r$-hitung semuanya berada di atas $r$-kritis yaitu berada di atas 0,3 , ini menunjukkan bahwa seluruh butir pertanyaan dalam kuesioner dinyatakan valid.

\section{Uji Reliabilitas}

Berdasarkan tabel diatas diketahui bahwa nilai Cronbach's Alpha semua variabel diatas 0,8 artinya berada pada kategori reliabilitas baik. Hal ini menunjukkan bahwa variabel minat beli dinyatakan reliabel.

\section{Uji Asumsi Klasik}

\section{Uji Normalitas}

Berdasarkan pengujian normalitas yang dapat dilihat pada gambar di atas,pada plot normal dapat disimpulkan bahwadistribusi data mendekati normal karena tidak ada penyimpangan yang mencolok dari kurva garis normal. Model regresi dikatakan memenuhi asumsi normalitas 
jika data menyebar disekitas garis diagonal dan mengikuti arah garis diagonal. Sehingga dapat dikatakan bahwa semua variabel dalam penelitian ini memiliki sebaran data yang normal

\section{Uji Multikolinearitas}

Berdasarkan hasil pengujian multikolinieritas yang dapat dilihat pada tabel di atas ini menunjukkan bahwa nilai tolerance lebih dari 0,01 dan nilai Variance Inflation Faktor (VIF) kurang dari 10 sehingga dapat dikatakan bahwa dalam penelitian ini tidak terjadi multikolinieritas antar variabel bebas (independen). Selain itu, tidak terjadinya multikolinieritas yang serius.

\section{Uji Heterokedastitas}

Berdasarkan grafik scaterplot menunjukan bahwa tidak terdapat polayang jelas serta titik yang menyebar diatas dan dibawah angka 0 padasumbu Y. Sehingga dapat disimpulkan tidak terjadi heteroskedastisitas padamodel regresi

\section{Uji Autokorelasi}

Berdasarkan tabel 4.14 dengan perhitungan SPSS didapatkan nilai DurbinWatson 1.861. Sedangkan nilai du dapat dilihat pada table dengan jumlah data $(n)=126$ dan jumlah variabel independen $(\mathrm{k})=2$, nilai du $=1,7415$, nilai $4-\mathrm{du}=2,2585$. Karena nilai Durbin Watson berada diantara du dan 4 - du yaitu $1,7415<1,861<2,2585$ sehingga terbukti tidak terjadi autokorelasi dan dapat digunakan untuk analisis selanjutnya

\section{Analisis Regresi Linear Berganda}

Pengujian penelitian ini menggunakan Analisis regresi linier berganda.Dalam penelitian ini terdapat 2 (dua) variabel independen yaitu iklan dan wordof mouth serta variabel independen yaitu minat beli. Adapun penjelasannyasebagaiberikut:

Tabel 1. Analisis Regresi Linear Berganda

\section{Coefficients $^{\mathrm{a}}$}

\begin{tabular}{|c|c|c|c|c|c|}
\hline \multirow[t]{2}{*}{ Model } & $\begin{array}{l}\text { Unstandardized } \\
\text { Coefficients }\end{array}$ & $\begin{array}{l}\text { Standardized } \\
\text { Coefficients }\end{array}$ & & \multirow[t]{2}{*}{$\mathrm{t}$} & \multirow[t]{2}{*}{ Sig. } \\
\hline & B & Std. Error & Beta & & \\
\hline (Constant) & 3.103 & 1.028 & & 3.017 & .003 \\
\hline Iklan (X1) & .601 & .085 & .483 & 7.050 & .000 \\
\hline Word of Mouth (X2) & .577 & .085 & .466 & 6.803 & .000 \\
\hline
\end{tabular}

a. Dependent Variable: Minat Beli (Y)

Sumber: Data Diolah SPSS, 2021

Berdasarkan hasil analisis dari tabel di atas dapat dijelaskan, koefisien-koefisien persamaan regresi sebagai berikut:

$\beta=3.103$

$\mathrm{X} 1=0.601$

$\mathrm{X} 2=0.577$

Sehingga persamaan regresi linier berganda pada penelitian ini adalah:

\section{$\mathrm{Y}=3.103+0.601 \mathrm{X} 1+0.577 \mathrm{X} 2$}

Dari persamaan tersebut, maka dapat djelaskan sebagai berikut:

a. Nilai Konstanta $\beta 0=3.103$ artinya menunjukkan besarnya variable minat beli yang tidak dipengaruhi oleh iklan danword of mouth atau dapat diartikan pada saat nilai iklan dan word of mouth sama dengan nol (0) atau tidak mengalami perubahan maka nilai minat beli sebesar 3.103. 
b. Koefisien regresi untuk variable iklan (X1) sebesar 0.601 artinya iklan memiliki hubungan positif atau searah dengan minat beli.

c. Koefisien regresi untuk variable word of mouth (X2) sebesar 0.577 artinya word of mouth memiliki hubungan positif atau searah dengan minat beli

\section{Koefisien Determinasi}

Tabel 2. Koefisien Determinasi

\begin{tabular}{|c|c|c|c|c|}
\hline \multicolumn{5}{|c|}{ Model Summary ${ }^{b}$} \\
\hline Model & $\mathrm{R}$ & R Square & Adjusted R Square & Std. Error of the Estimate \\
\hline 1 & $.909^{\mathrm{a}}$ & .827 & .824 & 2.155 \\
\hline
\end{tabular}

Sumber: Data Diolah SPSS, 2021

Berdasarkan tabel diatas diperoleh informasi bahwa R-square sebesar 0.827 atau 82,7\%. Nilai tersebut menunjukkan bahwa iklan dan word of mouth, secara simultan dalam memberikan kontribusi atau pengaruh terhadap minat beli sebesar $82,7 \%$, sedangkan sisanya sebesar $100 \%$ $-82,7 \%=17,3 \%$ merupakan pengaruh dari variable lain yang tidak diteliti.

Sedangkan untuk melihat besar penaruh dari masing-masing variable bebas terhadap variable terikat, dilakukan perhitungan dengan menggunakan formula Beta x Zero Order $\mathrm{x}$ $100 \%$.. Beta adalah koefisien regresi yang telah distandarkan, sedangkan zero order merupakan korelasi parsial dari setiap variable bebas terhadap variable terikat. Dengan menggunakan SPSS diperoleh nilai Beta dan zero order sebagai berikut:

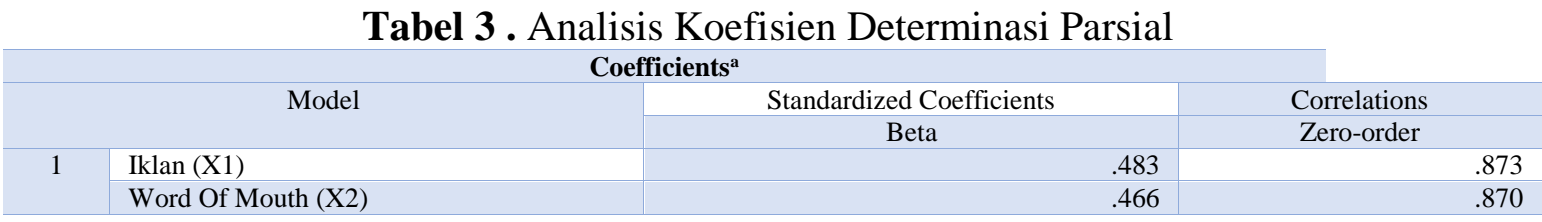

a. Dependent Variable: Minat Beli (Y)

Sumber: Data Diolah SPSS, 2021

Berdasarkan tabel diatas dapat dilakukan perhitungan memperoleh pengaruh parsial dari setiap variable sebagai berikut:

$\operatorname{Iklan}\left(\mathrm{X}_{1}\right) \quad: 0.438 \times 0.873 \times 100 \%=0.422$ atau $42.2 \%$

Word Of Mouth $\left(\mathrm{X}_{2}\right): 0.466$ × $0.870 \times 100 \%=0,405$ atau $40.5 \%$

Berdasarkan perhitungan di atas, diketahui bahwa pengaruh terbesar dari variabel iklan $\left(\mathrm{X}_{1}\right)$ dengan kontribusi pengaruh sebesar $42.2 \%$ sedangkan variabel word of mouth $\left(\mathrm{X}_{2}\right)$ memberikan kontribusi pengaruh sebesar $40.5 \%$.

\section{Uji Hipotesis}

Uji F (Uji Simultan)

Hasil uji simultan dapat dilihat pada tabel dibawah sebagai berikut:

Tabel 4. Uji F (Uji Simultan)

\begin{tabular}{|c|c|c|c|c|c|c|}
\hline \multicolumn{7}{|c|}{ ANOVA $^{\mathrm{a}}$} \\
\hline \multicolumn{2}{|c|}{ Model } & Sum of Squares & df & Mean Square & $\mathrm{F}$ & Sig. \\
\hline \multirow[t]{3}{*}{1} & Regression & 2727,453 & 2 & 1363,727 & 293,718 & $.000^{\mathrm{b}}$ \\
\hline & Residual & 571,086 & 123 & 4,643 & & \\
\hline & Total & 3298,540 & 125 & & & \\
\hline \multicolumn{7}{|c|}{ a. Dependent Variable: Minat Beli (Y) } \\
\hline
\end{tabular}

Sumber: Data Diolah SPSS, 2021 
Berdasarkan hasil perhitungan yang terlihat pada tabel ANOVA, di peroleh $F_{\text {hitung }}$ sebesar 293.718 sedangkan nilai $\mathrm{F}_{\text {Tabel }}$ pada taraf nyata $(\alpha) 5 \%$ dengan derajat bebas $\mathrm{V}_{1}=\mathrm{k} ; \mathrm{V}_{2}=\mathrm{n}$ $\mathrm{k}-1=126-2-1=123$ ialah 3.07. Artinya nilai $\mathrm{F}_{\text {Tabel }}$ sebesar 3.07. Hasil perhitungan statistik menunjukkan nilai $\mathrm{F}_{\text {hitung }} 37.605>\mathrm{Ft}_{\text {abel }} 3.09$. Nilai signifikasi $0.000<0.05$, hal tersebut berarti secara simultan iklan dan word of mouth berpengaruh signifikan terhadap minat beli online melalui aplikasi Shopee pada Mahasiswa Fakultas Ekonomi Universitas Nasional Pasim.

\section{Uji t (Uji Parsial)}

Hasil uji parsial dapat dilihat pada tabel dibawah sebagai berikut:

\begin{tabular}{|c|c|c|c|c|c|}
\hline \multicolumn{6}{|c|}{$\begin{array}{c}\text { Tabel 5. Uji t (Uji Parsial) } \\
\text { Coefficients }\end{array}$} \\
\hline Model & $\begin{array}{l}\text { Unstandardized } \\
\text { Coefficients }\end{array}$ & $\begin{array}{l}\text { Standardized } \\
\text { Coefficients }\end{array}$ & & $\mathrm{t}$ & Sig. \\
\hline (Constant) & 3103 & Std. Error & Beta & 2017 & 002 \\
\hline Iklan (X1) & .601 & .085 & .483 & 7.050 & .000 \\
\hline Word of Mouth (X2) & .577 & .085 & .466 & 6.803 & .000 \\
\hline
\end{tabular}

a. Dependent Variable: Minat Beli (Y)

Sumber: Data Diolah SPSS, 2021

Uji t dengan tingkat $\alpha=5 \%$, diketahui $n=126$, dengan $\mathrm{df}=\mathrm{n}-2$ yaitu $\mathrm{df}=124$ adalah 1.979 . Artinya nilai $\mathrm{t}_{\text {tabel }}$ 1.979. dapat di interprestasikan sebagai berikut:

a) Nilai sig.t hitung iklan $0,438>$ nilai alpha yaitu 0,05 dan nilai $t_{\text {hitung }} 7.050>t_{\text {tabel }} 1.979$ berarti variable iklan secara parsial berpengaruh signifikan.

b) Nilai sig.t hitung word of mouth $0,466>$ nilai alpha yaitu 0,05 dan nilai $\mathrm{t}_{\text {hitung }} 6.803>\mathrm{t}_{\text {tabel }} 1.979$ berarti variable word of mouth secara parsial berpengaruh signifikan.

\section{Bagaimana Iklan Shopee di Instagram}

Berdasarkan hasil penelitian dan pengolahan data diketahui bahwa variabel iklan berada pada kategori baik, namun masih terdapat aspek yang lemah mengenai pesan yang disampaikan dalam iklan belum optimal, terkait hal tersebut Shopee sebaiknya meninjau kembali pesan yang disampaikan dalam iklan di Instagram, hal yang bisa dilakukan dengan memilih kata yang mudah dipahami dan memperjelas keterangan dari gambar yang ditampilkan, karena iklan merupakan salah satu faktor yang mempengaruhi minat beli konsumen.

\section{Bagaimana Word Of Mouth pada Aplikasi Shopee}

Berdasarkan hasil penelitian dan pengolahan data diketahui bahwa variabel word of mouth berada pada kategori baik, namun masih terdapat aspek yang lemah mengenai informasi ketidaksesuaian terhadap barang yang dipesan, terkait hal tersebut 2. Shopee disarankan memperhatikan terkait informasi negatif yang mudah sampai dari konsumen ke konsumen, seperti ketidaksesuaian produk pesanan yang dikirim oleh penjual Shopee.

\section{Bagaimana Minat Beli Online Melalui Aplikasi Shopee}

Berdasarkan hasil penelitian dan pengolahan data diketahui bahwa variabel minat beli berada pada kategori baik, namun masih terdapat aspek yang lemah mengenai tingkat kepuasan konsumen masih belum optimal, Shopee diharapkan meningkatkan pelayanan agar konsumen merasa puas, hal yang bisa dilakukan Shopee diharapkan meningkatkan pelayanannya agar konsumen puas.. 


\section{Pengaruh Iklan Terhadap Minat Beli Online Melalui Aplikasi ShopeePada Mahasiswa Fakultas Ekonomi Universitas Nasional Pasim}

Berdasarkan hasilpengujian parsial (uji t) untuk iklan $\left(X_{1}\right)$ signifikansi pada level 0,000. Sesuai dengan kriteria bila nilai signifikansi $<0.05(0.00<0.05)$ maka hipotesis yang diajukan yaitu $\mathrm{H} 1=\beta 1 \neq 0$, iklan berpengaruh positif terhadap minat beli dapat dikonfirmasi. Hal ini sesuai deengan hasil ujidengan nilai $t_{\text {hitung }} 7.050>\mathrm{t}_{\text {tabel }} 1.979$, makaHoditolak dan HAditerima, yang artinya iklan secara parsial berpengaruh signifikanterhadap minat beli online di Shopee. Iklan $\left(\mathrm{X}_{1}\right)$ memberikan kontribusi atau pengaruh terhadap minat beli sebesar $42.2 \%$.

\section{Pengaruh Word Of Mouth Terhadap Minat BeliOnline Melalui Aplikasi ShopeePada Mahasiswa Fakultas Ekonomi Universitas Nasional Pasim}

Berdasarkan hasil pengujian parsial (uji t)untukwordofmouth $\left(\mathrm{X}_{2}\right)$ signifikansi pada level 0,000. Sesuai dengan kriteria bila nilai signifikansi $<0.05(0.00<0.05)$ maka hipotesis yang diajukan yaitu $\mathrm{HA}=\beta 1 \neq 0$, word of mouth berpengaruh positif terhadap minat beli dapat dikonfirmasi.Hal ini sesuai dengan hasil ujidengan nilaithitung6.803>t tabel 1.979 , maka Hoditolak dan HAditerima, yang artinyaword of mouth berpengaruh signifikan terhadap minat beli ulang secara online di Shopee. Word of mouth $\left(\mathrm{X}_{2}\right)$ memberikan kontribusi atau pengaruh terhadap minat beli sebesar $40.5 \%$.

\section{Pengaruh Iklan Dan Word Of Mouth Terhadap Minat BeliOnline Melalui Aplikasi Shopee Pada Mahasiswa Fakultas Ekonomi Universitas Nasional Pasim}

Berdasarkan hasil pengujiansimultan (uji F) didapatkan nilai $F_{\text {hitung }} 293.718>F_{\text {tabel }} 3.07$ dengan nilai signifikasi $<0.05 \quad(0.00<0.05)$. hal tersebut berarti secara simultan iklandanwordofmouthberpengaruh signifikan terhadapminatbeli online melalui aplikasi Shopee pada Mahasiswa Fakultas Ekonomi Universitas Nasional Pasim.Iklan dan word of mouth, secara simultan dalam memberikan kontribusi atau pengaruh terhadap minat beli sebesar 0,827 atau $82,7 \%$.

\section{KESIMPULAN}

Berdasarkan data yang diperoleh dan hasil pengolahan data dalam penelitin ini dapat ditarik kesimpulan sebagai berikut:

1. Iklan di Instagram termasuk dalam kategori baik, namun masih terdapat aspek yang lemah mengenai pesan yang disampaikan dalam iklan belum optimal.

2. Word of mouth termasuk dalam kategori baik, namun masih terdapat aspek yang lemah mengenai informasi ketidaksesuaian terhadap barang yang dipesan.

3. Minat beli termasuk dalam kategori baik, namun masih terdapat aspek yang lemah mengenai tingkat kepuasan konsumen belum optimal.

4. Iklan di Instagram secara parsial berpengaruh positif signifikan terhadap minat beli onlinemelalui aplikasi Shopee pada mahasiswa Fakultas Ekonomi Universitas Nasional Pasim.

5. Word of mouth secara parsial berpengaruh positif signifikan terhadap minat beli online melalui aplikasi Shopee pada mahasiswa Fakultas Ekonomi Universitas Nasional Pasim.

6. Iklan di Instagram dan Word of Mouth secara simultan berpengaruh positif signifikan terhadap minat beli online melalui aplikasi Shopee pada mahasiswa Fakultas Ekonomi Universitas Nasional Pasim. 


\section{DAFTAR PUSTAKA}

Daulay, R. (2014). Pengaruh Kualitas Pelayanan dan Bagi Hasil Terhadap Keputusan Menabung Nasabah Pada Bank Mandiri Syariah di Kota Medan. Jurnal Riset Akuntansi \& Bisnis 12 (1).

Dwi Putranti, H. R., \& Suparmi, S. (2016). Pengaruh Kemasan Ramah Lingkungan dan Informasi Terhadap Minat Beli Ulang (Studi Konsumen AMDK Kota Semarang). Prosiding Seminar Nasional INDOCOMPAC.

Febiana, D. (2014). PENGARUH WORD OF MOUTH TERHADAP MINAT BELI SERTA DAMPAKNYA PADA KEPUTUSAN PEMBELIAN ( Survei pada Pengunjung yang Melakukan Pembelian pada Biker 's Resto dan Cafe di Kota Malang ). 16(1), 1-6.

Ferdinand, A. (2014). Pengembangan Minat Beli Merek Ekstensi. In Semarang: Badan Penerbit Universitas Diponegoro.

Hasan, A. (2010). Marketing dari Mulut ke Mulut, cetakan.1. In Yogyakarta: Media Pressindo. J. Paul dan Jerry C Olson, P. (2012). Perilaku Konsumen dan Strategi Pemasaran. In Jakarta: Erlangga.

Kotler, P., \& Keller, K. L. (2016). MarkKotler, P., \& Keller, K. L. (2016). Marketing Management. Global Edition (Vol. 15E). In Global Edition (Vol. 15E, Issue 4).

Mandasari, W. J. (n.d.). PENGARUH CITRA MEREK , KUALITAS PRODUK , HARGA , IKLAN DAN WORD OF MOUTH TERHADAP MINAT BELI YAMAHA N-MAX.

Priansa, D. (2017). Komunikasi pemasaran terpadu: Pada era media sosial. In Marketing Communication.

S. Soedibjo, B. (2013). Pengantar Metode Penelitian. In Bandung: Universitas Nasional Pasim (p. 102).

Sugiyono. (2017a). Metode Penelitian Bisnis (Pendekatan Kuantitatif, Kualitatif, Kombinasi dan R\&DSugiyono. (2017). Metode Penelitian Bisnis (Pendekatan Kuantitatif, Kualitatif, Kombinasi dan R\&D). In Metodelogi Penelitian.). In Metodelogi Penelitian.

Susanti, I., Syairozi, M. I., \& Lukman, H. Y. W. (2021). Analisis Sistem Manajemen Dalam Pengelolaan Bumdes Di Desa Bluluk. Jurnal Sains Sosio Humaniora, 5(2), 701-710.

Sugiyono, D. (2017b). Metode penelitian kuatintatif, kualitatif dan R \& D / Sugiyono. In Bandung: Alfabeta (Vol. 15, Issue 2010).

Syairozi, M. I., \& Fattah, A. (2018). "YOUTH CREATIVE ENTERPRENEUR EMPOWERMENT (YOUTIVEE)": SOLUSI BAGI KAUM MUDA UNTUK BERKONSTRIBUSI PADA PEREKONOMIAN DAN MENGURANGI PENGANGGURAN. Jesya (Jurnal Ekonomi dan Ekonomi Syariah), 1(2), 43-55.

https://www.itworks.id/42469/simak-nih-kinerja-platform-e-commerce-di-tanah-air-untuksemester-i.html, diunduh tanggal 7 September 2021

http://www.marketing.co.id/dulang-sukses-pemasaran-instagram-ini-strateginya/, _diunduh tanggal 7 September 2021 